\title{
The mealworm Tenebrio molitor (Coleoptera: Tenebrionidae) as a potential candidate to valorize crop residues
}

\author{
Jamaa Zim ${ }^{1 *}$ Mohammed Sarehane ${ }^{1}$ and Rachid Bouharroud $^{2}$ \\ ${ }^{1}$ Agronomic and Veterinary Institute Hassan II, Agadir, Morocco \\ ${ }^{2}$ Integrated Crop Production Unit, Centre Régional de la Recherche Agronomique d'Agadir \\ (INRA), Morocco
}

\begin{abstract}
Agricultural activities generate important amount of crop residues that need to be managed in appropriate way usingecofriendly and cost effective tools. The mealworm Tenebrio molitor (Coleoptera: Tenebrionidae) is a potential candidate to valorize crop residues thatcan produce atthe same time an alternative feed based on insect larvae. Four crop residues (citrus, tomato, pepper and potato) mixedwith wheat bran (ratio 50:50) were evaluated as diets for mass rearing of $T$. molitor under controlled environmental conditions $\left(\mathrm{T}=28 \pm 1{ }^{\circ} \mathrm{C} ; \mathrm{RH}=70 \pm 5 \%\right.$ and total darkness). Five zootechnical parameters (weight gain, growth rate, mortality rate, weight of consumed feed and conversion rate) were adopted to evaluate thegrowth and life developmental traits of larvae during 45 days. The effect of crop residues used as diet had a significant impact on bothweight gain and growth rate. Importantly, crop residues used alone has a negative effect on all zootechnical parameters evaluated. Indeed, the amendment of wheat bran has a significant positive impact on these parameters. Citrus and tomato were the most toxic diets showing a mortality rate of 92 and $98 \%$, respectively. The most efficient diets werethe mixture of citrus residues andwheat branfollowed by the mixture of potato residues and wheat bran and the mixture ofpepper residues and wheat bran. Fed substrate had no impact on conversion rate.
\end{abstract}

\section{Introduction}

Crop residues management and valorization raise more and more concern in environment departments in many countries. In the Souss valley (Southwest of Morocco), considered as the main region of production and export of vegetables and

*Corresponding author: j.zim@,iav.ac.ma 
fruits in Morocco, the annual crop residues was estimated at 3.4 tons in 2020 [1]. The residues and wastes from crops arenot usually easy to manage and a non-appropriate practice led to create a perfect environment in which varieties of pests and pathogens can develop and multiply [2]. Burning these residues has a negative impact on the emission of greenhouses gases [3]. As a result, poor waste management can pose a serious danger to surrounding crops and to the environment as they resist biodegradation, resulting in requirements of harsher pretreatment [4].

The yellow mealworms Tenebrio molitor Linnaeus (1758), has a four-stage life cycle: egg, larva, pupa and adult [5]. The larvae are raised as feed for birds, reptiles, amphibians, and fish using wheat bran (WB) as the primary feedstock, an agricultural by-product [6]. This insect is a considered as a more sustainable source of human edible protein compared tomilk, chicken, pork or beef [7].

Recent studies point to mealworms as an acceptable alternative source of protein for broiler chickens [8]. More than a million tons of mealworms are produced in China for domestic use and export as animal feedstock [9]. Mealworms are also considered as a valuable source of protein for insects in the USA and Europe [8]. Mealworms have also a biodegrading ability of plastic foams of polystyrene (PS) and polyethylene (PE) up to $50 \%$ after they have been absorbed into their guts $[9,10]$; suggesting that mealworms have powerful digestive systems.

We hypothesized that the use of insects isa more economically feasible and environmentally friendly approach to convert crop residues into biomass and simple organic materials: a concept called biotransformation. This solution is sustainable, ecological and above all cost effictive. We plan to use a $T$. molitor, as a recycling engine for crop residues, producing a promising source of protein for animal feed. Researches have been done on different crop residues such as wheat straw, rice bran, maize straw and rice straw [9] but not on vegetables and fruits residues such as tomato, pepper and citrus.

This trial is a preliminary step carried out in order to evaluate the capacity of T. molitor larvae to transform vegetable and fruit wastes to resolve the issue of crop residue management and to reduce the production cost of these larvae mainly intended for animal feed.

\section{Material and methods}

\subsection{Site of the experiment}

The crop residues (citrus, tomato, pepper and potato) were collected from the experimental farm of the Agronomic and Veterinary Institute, Complexe HorticoleAgadir $\left(30^{\circ} 21^{\prime} 12.0^{\prime \prime} \mathrm{N} 9^{\circ} 28^{\prime} 38.8^{\prime \prime} \mathrm{W}\right)$. Crop material was dried in a plastic greenhouse at ambient temperature for 8 days, then the dry residues were grinded with an electric grain mill $(25000 \mathrm{rpm})$. After weighing, the residues were put back in the greenhouse for 48 hours to be furtherdried. This operation has been repeated until the weight was stabilized. Twenty five $\mathrm{mg}$ of residue substrates were placed in cylindrical plastic boxes ( $7 \times 5 \mathrm{~cm}$, diameter and height) with smooth walls to prevent the larval escape. Table 1 shows the proportions of the 10 substrates used in this study. 


\subsection{Diets}

The diet used for stock mass rearing and as control was prepared from wheat bran $(60 \%)$ completed with animal feed (starter feed for broiler chicken, ALF ISSAN company) containing $20 \%$ of crude protein. Larva ( $22 \pm 3$ days) were collected from a mass rearing carried out in the entomology laboratory of the Agronomic and Veterinary Institute, ComplexeHorticole-Agadir. In order to have homogeneous population of larvae, adults in peak of reproduction period were randomly selected and reared in large size boxes $\left(\mathrm{L}=41, \mathrm{l}=28\right.$ and $\mathrm{H}=7 \mathrm{~cm}$ ) with a rearing density of 1 adult $/ \mathrm{cm}^{2}$, in the same diet (control). To serve as a water source and moisture, pieces of potato were added every 4 days. After 3 days the eggs were collected using a large-mesh sieve to separate the adults from the substrate containing the eggs, which will hatch after4 days (Cotton 1927). After 22 days the larvae were isolated from the substrate and put to fast for 24 hours before trials. Random samples of 100 larvae (average weight of a larva is $0.0011 \pm 0.0001 \mathrm{~g}$ ) were added in the boxes containing substrate. The boxes were placed according to a completely randomized experimental design in a rearing chamber $(2.8 \times 2.9 \times 2.5 \mathrm{~m})$ under controlled environmental conditions $\mathrm{T}=28 \pm 1^{\circ} \mathrm{C} ; \mathrm{RH}=70 \pm 5 \%$ and total darkness.

In order to evaluate the effect of dry crop residues on the growth and biomass gain of $T$. molitor, we focused on four zootechnical parameters measured after 45 days of rearing which are the most important in mass rearing.

- Weight gain $=$ Final weight $($ after 45 days $)-$ initial weight

- $\quad$ Mortality rate $=\frac{\text { initial number of individuals }-N \quad \text { of individuals after } 45 \text { days }}{\text { Initial number of individuals }}$

- Weight of consumed feed $=$

The initial weight of food - The final weight of food

- $\quad$ Conversion rate $=$ Weight gain - weight consumed

The crop residues used of tomato, pepper and citrus were the residues left from routine operations performed during the whole crop cycle (e.g. pruning).

\subsection{Data analysis:}

In this study, 9 substrates and control were studied. Each treatment was repeated 4 times. The recording of the results and the graphs were made with Excel software (version 2016). The statistical analysis of the results of this study was carried out using MINITAB software (version 2016) for the analysis of variance (ANOVA), using the general linear model procedure $(\alpha=0.05)$. The Tuckey test was used to compare the means between different treatments (significance level $\mathrm{P} \leq 0.05$ ). 
Table 1.Composition of the substrates used in the experiment.

\begin{tabular}{c|l}
\hline Substrate & \multicolumn{1}{c}{ Composition } \\
\hline S1 & Tomato residue $50 \%+$ Wheat bran $50 \%$. \\
\hline S2 & Tomato residue \\
\hline S3 & Potato residue $50 \%+$ Wheat bran $50 \%$ \\
\hline S4 & Potato residue \\
\hline S5 & Pepper residue $50 \%+$ Wheat bran $50 \%$ \\
\hline S6 & Pepper residue \\
\hline S7 & Citrus residue $50 \%+$ Wheat bran $50 \%$ \\
\hline S8 & Citrus residue \\
\hline S9 & $25 \%$ of each of the 4 crop residues (pepper, tomato, potato and citrus) \\
\hline Control & Wheat bran $60 \%+$ Starter feed for broiler chicken $40 \%$ \\
\hline
\end{tabular}

\section{Results}

\subsection{Weight Gain and growth rate}

The type of substrate used for mass rearing of T. molitor has a very significant effect on the weight gain and growth rate (Figure 1; F=113.21; $\mathrm{P}=0.000$ ). The control showed the highest weight gain and growth rate $(3.0024 \mathrm{~g}$ and $0,0751 \mathrm{~g} /$ day, respectively) for a means of samples of 150 larva over 45 days. The second diet with thehighest weight gain and growth rate was S8 containing $50 \%$ of citrus residues and $50 \%$ of wheat bran $(2.1635 \mathrm{~g})$. The other substrates also showed a moderate weight gain and growth rate. The main observation is that the use of dried crop residues-based diet alone caused a significant weight loss.

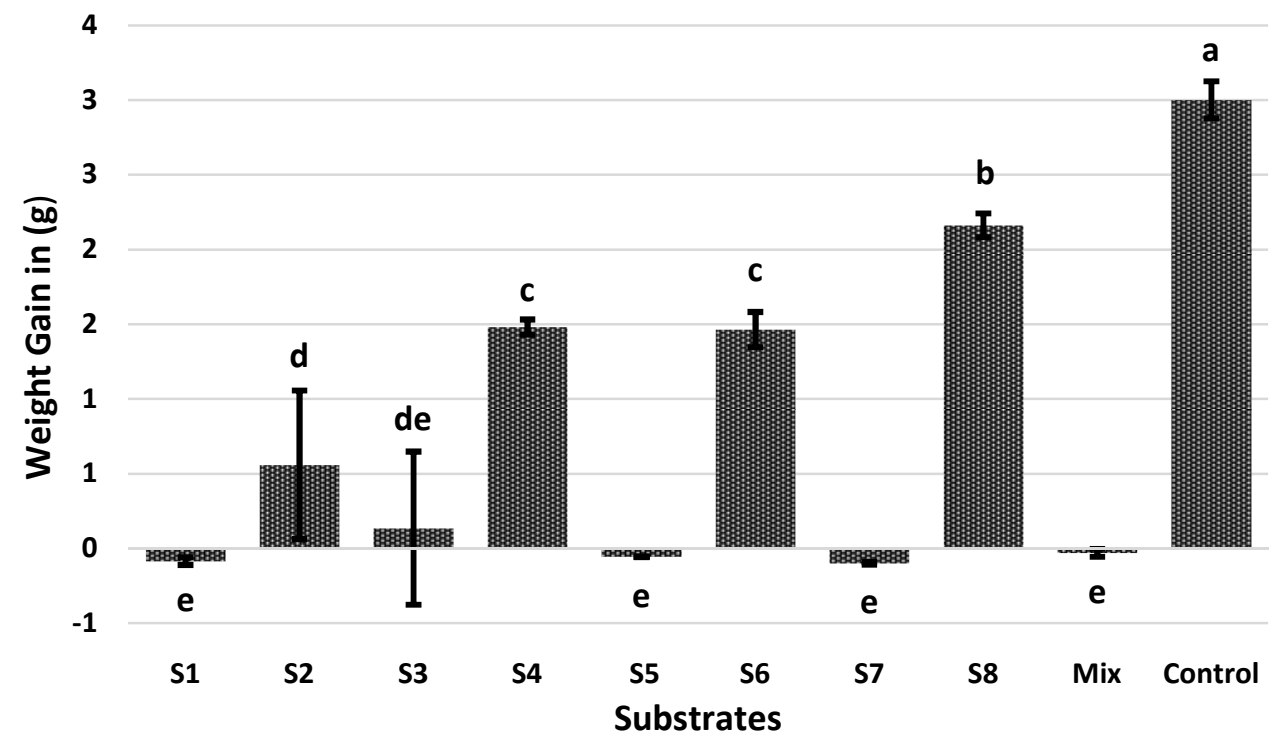


Fig.1.Effect of 10 substrates tested on the weight gain of T. molitor. The means followed by the same letter are not statistically different at $\mathrm{P}<5 \%$ according to the Tukey test.

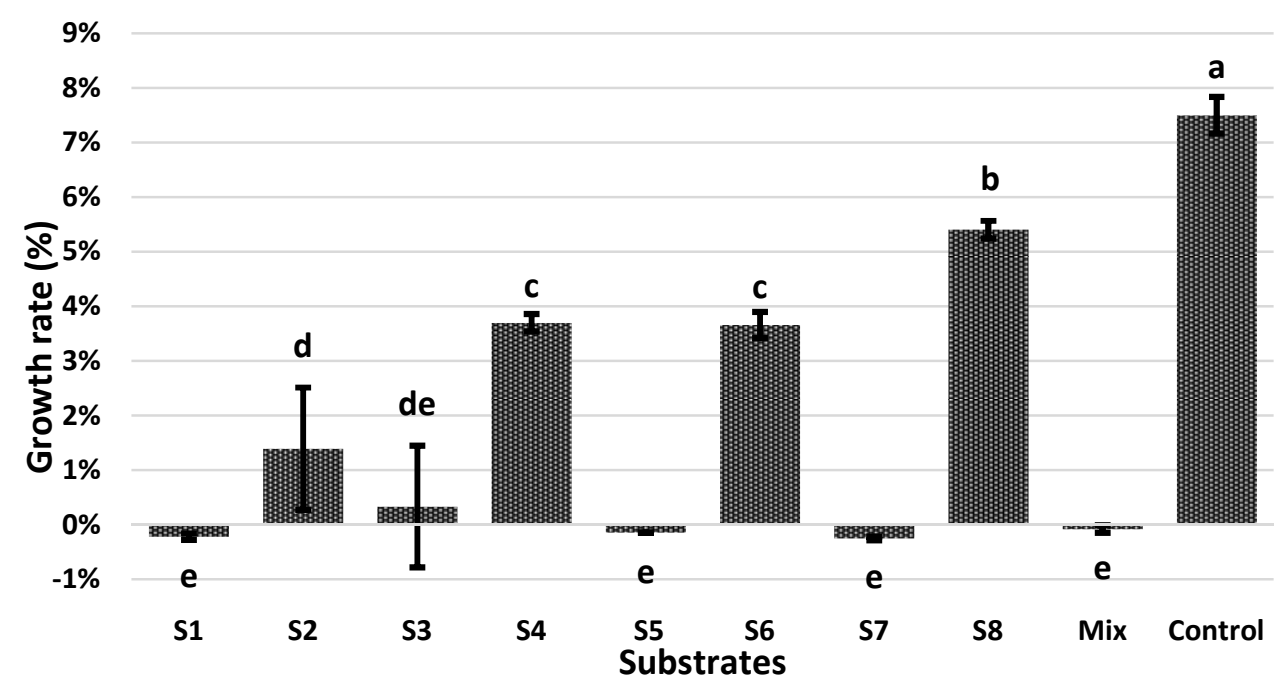

Fig.2.Effect of 10 substrates tested on the growth rate of T. molitor. The means followed by the same letter are not statistically different at $\mathrm{P}<5 \%$ according to the Tukey test.

\subsection{Mortality rate}

The analysis of variance for mortality rates showed a highly significant effect of substrate types on the mortality rates of T. molitor larvae (Figure 2; $\mathrm{F}=117,18 ; \mathrm{P}=0.000$ ). Based on the Tukey test for means comparison, the lowest mortality rates (less than $7 \%$ ) were obtained in the control boxes and the 4 substrates containing $50 \%$ of wheat bran in addition to dried crop residues of citrus, pepper, tomato and potato. However, the substrates based on the dried citrus, pepper and tomato residues caused the most toxic effect to the larvae of T. molitor $(80.75,92.00$ and $98.00 \%$, respectively). The substrates S5 (potato) and S9 (mixture of $25 \%$ of the 4 crop residues) caused a moderate mortality rate (48.25 and $32.00 \%$, respectively). 


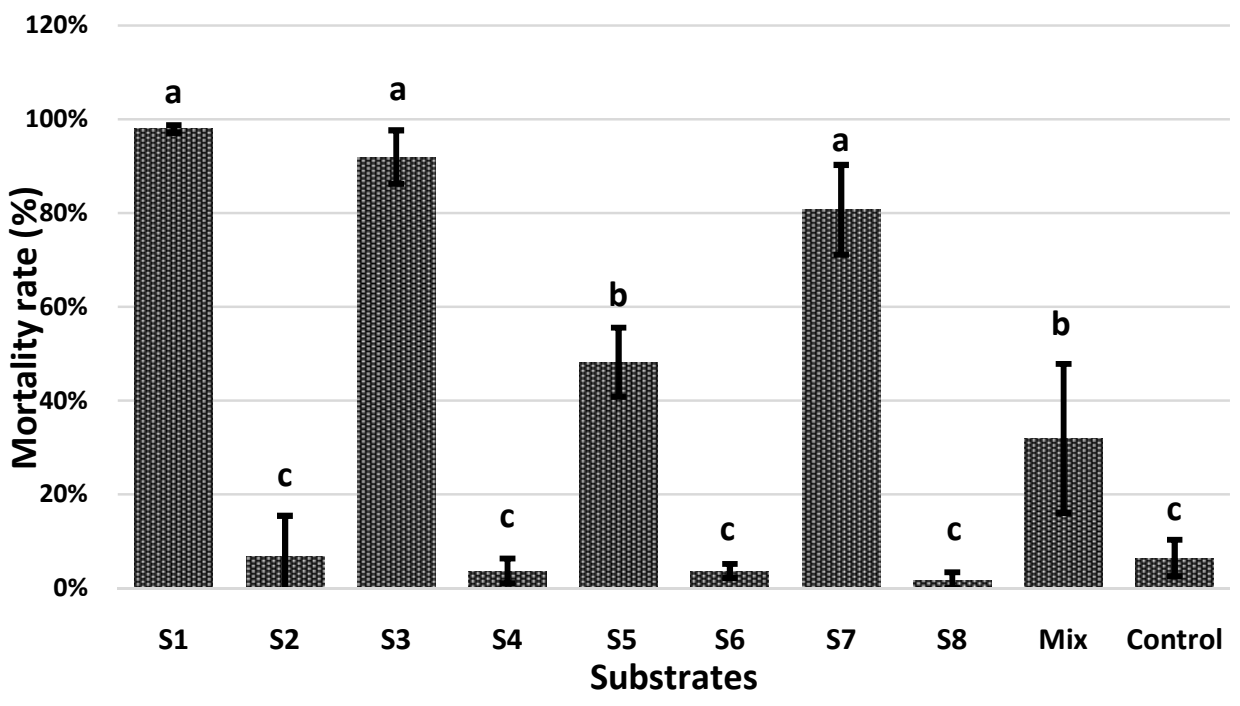

Fig.3. Effect of 10 substrates tested on the mortality rate of T. molitor. The means followed by the same letter are not statistically different at $\mathrm{P}<5 \%$ according to the Tukey test.

\subsection{Weight of consumed substrate}

The type of substrates used for rearing had a highly significant impact on the weight of consumed substrate (Figure 3; F=318.66 $\mathrm{P}=0.000$ ). The mean comparisons test (Tukey) at a confidence limit of $95 \%$ showed that the control was the most consumed substrate $(8.6238 \mathrm{~g})$ followed by the substrate S8 based on $50 \%$ wheat bran and $50 \%$ dry citrus residue (5.0445 g). The third group was composed of 2 substrates S4 and S6 which are made by the mixture of $50 \%$ wheat bran and $50 \%$ dry potato or dry pepper waste. The highest mortality rates observed were in the substrates based only ofdried crop residues (without wheat bran), these residues also had a negative impact on the weight of consumed substrates. 


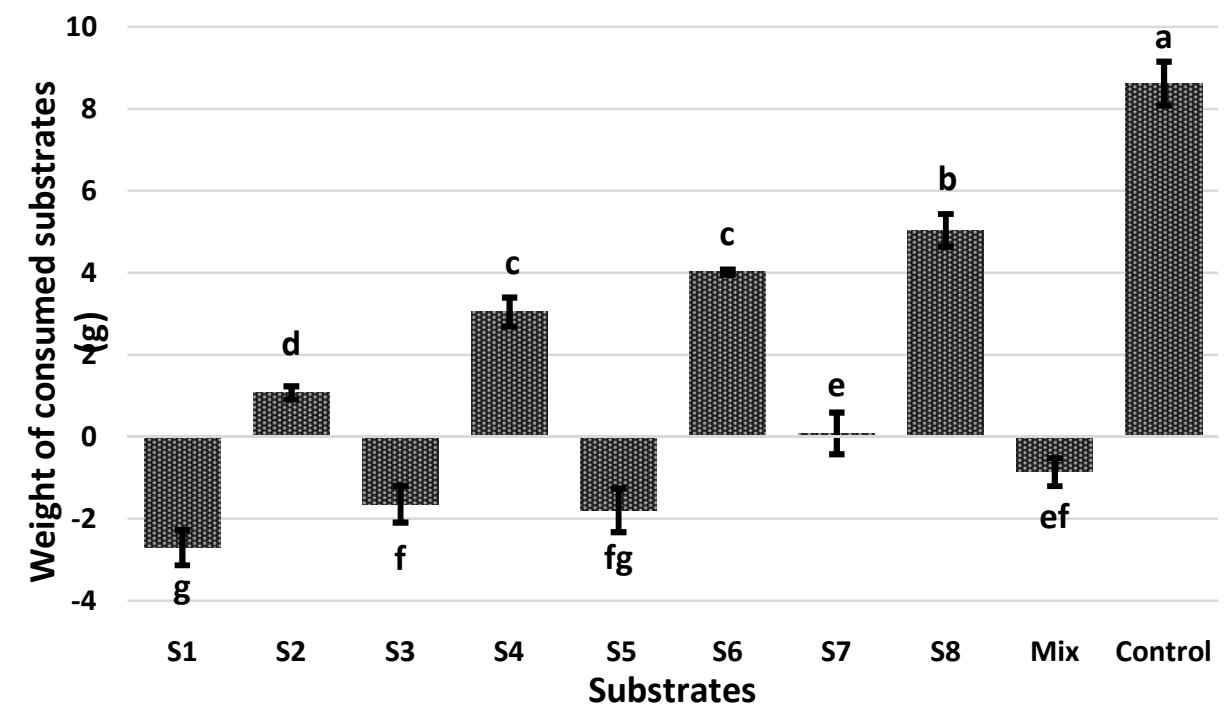

Fig.4.Effect of 10 substrates tested on the weight of consumed substrates of T. molitor. The means followed by the same letter are not statistically different at $\mathrm{P}<5 \%$ according to the Tukey test.

\subsection{Conversion rate}

Analysis of variance showed no significant effect of substrates on the conversion rate (Figure 4; $\mathrm{P}=0.631$ ).

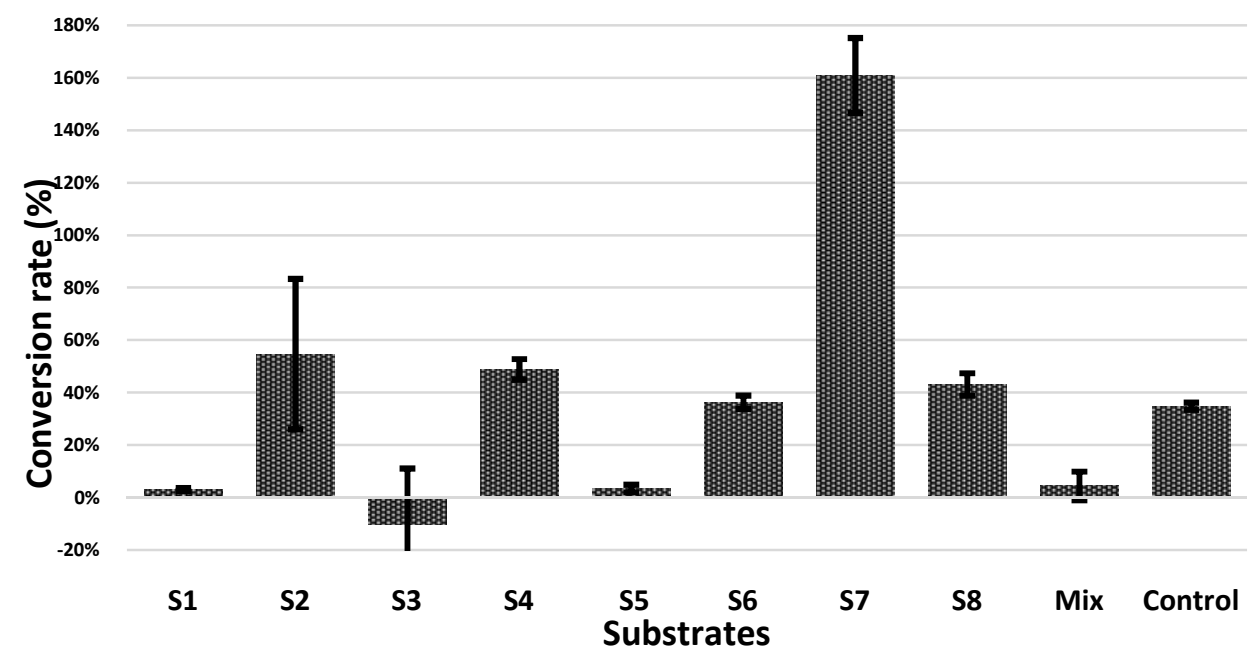

Fig.5. Effect of 10 substrates tested on the mortality rate of T. molitor. The means followed by the same letter are not statistically different at $\mathrm{P}<5 \%$ according to the Tukey test. 


\section{Discussion}

The new concept of insect-based bioremediation using agricultural waste as feedstock promises an alternative to fossil resources to produce biodiesel and proteins, thereby mitigating climate change and improving energy, animal feed and food safety [11]. Sustainability is becoming increasingly important worldwide. This study has shown that the use of substrates based on crop residues: tomato, pepper, potato and citrus, as a single food for $T$. molitor larvae, blocks their growth and also causes a very high mortality rate. However, if the residues are mixed with wheat bran, the larvae gain some biomass, but it is still an unsatisfactory gain compared to our control or wheat bran alone. Our results are not far from those of [12] even though the wastes used are different from those used in our trial. In the study of Ramos-Elorduyet al. (2002), authorsused waste mixtures at variousproportions and showed that: a diet consisting of $80 \%$ dry organic waste mixture of fruit and vegetables, $5 \%$ yeast and $15 \%$ excretion of T. molitor showed a performance in weight gain of mealworms and a richness in proteins and energy. The mortality rate was also very low and did not exceed $7 \%$ except for the Tomato residues diet, which shows that the wastes, subjects of the test, are non-toxic, however, their nutrient intake remains low, which explains the drop in the zootechnical performance of the larvae of T. molitor. Citrus residues are much better than other residues in terms of substrate, substituting the ordinary control feed for raising the mealworm larvae. This low growth rate caused by the mixtures, compared to the wheat bran diet, indicates that the mealworms were not able to select the correct feed when mixed with other less favorable feeds. Probably the most effective way to correct nutritional imbalances is to seek nutritionally complementary foods $[13,14]$.

\section{Conclusions andrecommendations}

In light of these results, it can be concluded that it is possible to incorporate a small amount of crop residues, especially from citrus, into the diet of Tenebrio molitor larvae. The valorization of driedcrop wastes is influenced, in the first instance, by the growth of the larvae. Further trials on a wide range of locally produced wastes need to be carried out in order to find which wastes are more important to include in the diet of the mealworms. In countries where wheat bran is cheaper, its use as a main diet is recommended in industrial farms. The evaluation of the potential of the mealworms as a leader insects in waste recovery can solve the waste problem and give an ideal alternative to the classical method used in the management of organic waste in its broadest sense.

\section{References}

1. Agence pour le Développement Agricole (ADA), Evaluation environnementale stratégique du Plan Maroc Vert Rapport définitif - Pages 82-83 (2012).

2. Cruz, D.; Cisneros, R.; Benítez, Á.; Zúñiga-Sarango, W.; Peña, J.; Fernández, H.; Jaramillo, A. Agronomy 11, 2362,( 2021).

3. Zhang, H.; Hu, D.; Chen, J.; Ye, X.; Wang, S. X.; Hao, J. M.; Wang, L.; Zhang, R.; An, Z. Environmental Science \& Technology. 45 (13): 5477-82 (2011).

4. Mussoline W., Esposito G., Giordano A., Lens P.(2013).

5. Roberson, W.H. Cambridge University Press, Cambridge, UK, pp. 126e127 (2005). 
6. Melis, R.; Braca, A.; Mulas, G.; Sanna, R.; Spada, S.; Serra, G.; Fadda, M.L.; Roggio, T.; Uzzau, S.; Anedda, R. Innov. Food Sci. Emerg. Technol. (2018).

7. Oonincx, D.G.A.B., De Boer, I.J.M. PLoS One 7, e51145 (2012).

8. Bovera, Fulvia\&Loponte, Rosa \&Marono, Stefania\& Piccolo, Giovanni \&Parisi, G. \&Iaconisi, V. \&Gasco, Laura \&Nizza, Antonino. Journal of Animal Science (2015).

9. Shan-Shan Yang, Yi-di Chen, Ye Zhang, Hui-Min Zhou, Xin-Yu Ji, Lei He, DeFeng Xing, Nan-Qi Ren, Shih-Hsin Ho, Wei-Min Wu. Environmental Pollution, Volume 252, Part B, Pages 1142-1153 (2019).

10. Brandon, Anja Malawi \& Gao, Shu-Hong \& Tian, Renmao\& Ning, Daliang\& Yang, Shanshan\& Zhou, Jizhong\& Wu, Weimin\&Criddle, Craig. Environmental Science \& Technology (2018).

11. Wang, H., Rehman, K.u., Liu, X. et al.. Biotechnol Biofuels 10, 304 (2017).

12. Ramos-Elorduy, Julieta\& González, Ernesto \& Hernández, Alma \&Pino, José. Journal of economic entomology (2002).

13. Waldbauer, G. P., \& Friedman, S. Annual Review of Entomology, 36(1), 43-63 (1991).

14. Behmer ST.. Annu Rev Entomol. (2009) 